\title{
RASGOS TRANSTEXTUALES DEL SURREALISMO ARGENTINO EN REVISTA QUÉ
}

Transtextual characteristics of Argentine surrealism in Magazine Qué

Felipe Gamboa Bravo*

\section{INTRODUCCIÓN}

El Surrealismo nace en 1924 con la aparición de "Primer manifiesto del surrealismo" de André Breton; con el pasar de los años este texto se convirtió en la piedra angular de los variados movimientos surrealistas en América Latina. La primera publicación surrealista latinoamericana fue la revista Qué, editada en Argentina en 1928, cuatro años después del texto fundacional de Breton.

Qué así como las diversas publicaciones surrealistas de América Latina, fue contrahegemónica, por lo que su circulación se restringió a amigos cercanos y círculos artísticos de carácter underground. Se publicaron solo dos números, el primero en 1928 y el segundo en 1930, ambos de tirajes limitados. Las publicaciones surrealistas en América Latina tuvieron en general tirajes escasos y nulas reediciones, por lo que son prácticamente inubicables hoy. La imposibilidad del acceso a las revistas y libros surrealistas explicaría en parte el actual vacío teórico y metodológico en América Latina.

Analizaremos textos teóricos publicados en los dos números de la revista Qué, los que dialogarán transtextualmente con los publicados por Breton en 1924 y 1930, "Primer" y "Segundo" manifiesto. De este diálogo transtextual se derivan cinco características relevantes del movimiento surrealista argentino: 1 . Crítica social y necesidad de libertad; 2. Pliegue sobre sí; 3. Epistemología del lenguaje; 4. Público y recepción y 5. Estética del sueño.

Debemos destacar que los textos publicados en Qué jamás han sido analizados semánticamente, por lo que esperamos que este trabajo contribuya al debate teórico y metodológico acerca del surrealismo latinoamericano.

\section{REVISTA QUÉ}

La revista Qué se publicó en la década del 20, época caracterizada por una gran efervescencia cultural; al respecto Méndez (2002) planteará: "Había en la ciudad de Buenos Aires, un clima cada vez más favorable a las innovaciones, a los cambios de costumbres, a las modas". En este contexto diversos movimientos reaccionaron ante el "rubenismo de princesas y cisnes", aunque no necesariamente contra Darío, sino que contra una literatura de conformidad (Sarlo, 1969, p. 9) que eludía las problemáticas y cuestionamientos sociales; por lo que se propusieron diversas alternativas estéticas. Varios de estos movimientos antihegemónicos plasmaron su concepción estética en revistas de limitada circulación; tal es el caso de Los raros (1920), de carácter futurista; Prisma 
(1921-1922) y Proa (1922-1926), revistas que posicionaron el movimiento ultraísta y a Jorge Luis Borges como su representante oficial; y, finalmente, Martín Fierro (19241927), publicación de carácter vanguardista donde se proclamó una "nueva sensibilidad" que con diversos matices se opuso a la estética oficial del periodo.

Dentro de este agitado panorama cultural Aldo Pellegrini - estudiante de medicinaserá deslumbrado por el "Primer manifiesto del surrealismo", texto publicado por Breton en 1924. Pellegrini comprendió que por medio de esta nueva estética era posible plasmar el inconformismo social y criticar la estética oficial del periodo. Luego de unos meses de "catecismo" (Baciu, 1979, p. 17), Pellegrini y sus compañeros de medicina publicaron en julio de 1928 la primera publicación surrealista de América Latina, la revista Qué.

El segundo y último número de la revista aparecerá dos años después, en diciembre de 1930. Pellegrini al recordar la génesis surrealista afirmará: "me llegó el primer número de La Révolution Surréaliste y el Primer manifiesto de Breton. Por entonces estudiaba medicina y hablé con entusiasmo a mis compañeros David Sussman y Mario Cassano, y después a Elías Piterbarg, quien trajo a su hermano Ismael y a Adolfo Solari. Todos formamos una especie de fraternidad surrealista, la que realizaba experiencias de escritura automática. La actividad de este grupo, totalmente desvinculado de las corrientes literarias de entonces, culminó con la publicación de los dos números de la revista Qué" (De Sola, 1967, p. 32).

De la primera revista Qué publicada en 1928 consideraremos tres textos: "Pequeño esfuerzo de justificación colectiva", texto inaugural y anónimo que funciona como editorial del primer número, "Pretexto" de Esteban Dalid (1928) (seudónimo de Elías Piterbarg) y el texto "Soluciones" de Julio Trizzi (1928) (seudónimo de David Sussman). En este primer número se publicaron diversos poemas y textos en prosa que evidencian la escritura automática como método de creación; reflexionando acerca del amor, la vida, la risa o temas variados. Los tres textos seleccionados tienen en común el carácter declarativo y reflexivo en relación con el sentido estético y vital del movimiento surrealista argentino.

De la segunda y última publicación de Qué aparecida en 1930, seleccionaremos cinco textos: "Respuesta" y "Manifiesto" de Esteban Dalid (seudónimo de Elías Piterbarg), los textos "Por esta puerta abierta los señores pueden entrar en el recinto de los fantasmas" y "Libertinaje de los solenoglifos, y otras cosas dichas entre dientes", ambos de Adolfo Este y Filidor Lagos (seudónimos de Aldo Pellegrini), y "Molestia. Como si fuera una aclaración para mí" de Julio Trizzi (seudónimo de David Sussman). La elección de estos cinco textos, y la no inclusión de los diversos textos en prosa y poemas que aparecen en las páginas del segundo número, al igual que la elección anterior, se relaciona con el carácter teórico y reflexivo que asumen estos escritos respecto de la estética surrealista argentina. En ambos números los autores publicaron con seudónimos que se expresan en la Tabla 1: 
Tabla 1: Autores de Qué y sus respectivos seudónimos

\begin{tabular}{|l|l|}
\hline \multicolumn{1}{|c|}{ Seudónimo } & \multicolumn{1}{c|}{ Autor } \\
\cline { 1 - 2 } Adolfo Este & \multirow{2}{*}{ Aldo Pellegrini } \\
\hline Filidor Lagos & \multirow{2}{*}{ Elías Piterbarg } \\
\hline Esteban Dalid & David Sussman \\
\hline Felipe Debernardi & Mario Cassano \\
\hline Julio Trizzi & Ismael Piterbarg \\
\hline Julio Lauretta & Raúl Pembo
\end{tabular}

Para profundizar el diálogo entre textos surrealistas separados por varios kilómetros, es relevante la precisión de Genette acerca de la "transtextualidad", la que explicará como "todo lo que pone al texto en relación, manifiesta o secreta con otros textos" (1989, p. 9). Genette distinguirá 5 variaciones o nociones de transtextualidad; sin profundizar el concepto, lo relevante es que permite atestiguar el diálogo entre textos dispares.

Los ocho textos seleccionados de ambas revistas dialogan de forma transtextual con "Primer manifiesto del surrealismo" (Breton, 1992b) y "Segundo manifiesto surrealista" (Breton, 1992a). No consideraremos para este estudio el "Tercer manifiesto surrealista" publicado en 1946, ni su adelanto "Prolegómenos a un tercer manifiesto o no" publicado en 1942, ya que ambos textos son posteriores a la publicación de Qué. Del diálogo transtextual, buscaremos establecer las principales características del movimiento surrealista argentino. Los textos publicados en Qué no han sido analizados críticamente, considerando similitudes y diferencias con los manifiestos franceses, de aquí la importancia y aporte de este trabajo, para contribuir al debate y análisis de la historia surrealista latinoamericana.

Si bien Qué contó solo con dos números publicados, fue la punta de lanza del movimiento surrealista latinoamericano. Todas las revistas surrealistas aparecidas posteriormente en Argentina y otros países latinoamericanos tuvieron una suerte similar, relacionada con un tiraje limitado y una circulación adscrita a un grupo restringido de simpatizantes. Estas publicaciones por su carácter contrahegemónico transitaron fuera de los circuitos oficiales. Los libros de autores surrealistas latinoamericanos, salvo contadas excepciones, tuvieron tirajes escasos y prácticamente nulas reediciones, por lo que son considerados como rarezas editoriales, inubicables para un lector común. La imposibilidad de acceder a las revistas y libros surrealistas explicaría en parte el actual vacío teórico y metodológico del surrealismo latinoamericano. Es importante destacar al respecto el aporte de la Universidad Nacional Autónoma de México (UNAM) al digitalizar y facilitar mediante internet, el libre acceso a las primeras revistas surrealistas latinoamericanas. Basado en lo anterior, comprendemos por qué escasean los análisis críticos y teóricos de los textos fundacionales del surrealismo latinoamericano, por lo que 
este trabajo se plantea como un aporte a la reconstrucción teórica del surrealismo argentino.

Debemos situar a Qué como punto inicial en la línea cronológica de las publicaciones surrealistas latinoamericanas y argentinas. Las publicaciones argentinas que continuaron la línea surrealista iniciada en Qué fueron: Ciclo (1948-1949), A partir de 0 (1952-1956) y Letra y linea (1953). Revistas que pese a su corta duración, posicionaron la estética surrealista en Argentina y Latinoamérica. En todas las publicaciones antes mencionadas participó de forma activa Aldo Pellegrini, por lo que debemos reconocer su importancia en la promoción y difusión del movimiento surrealista latinoamericano.

\section{DIÁLOGO TRANSTEXTUAL}

Analizaremos la manera en que los textos iniciales del surrealismo argentino, publicados en la revista Qué, dialogaron con los textos fundacionales del movimiento francés publicados por Breton, el "Primer" (1924) y "Segundo manifiesto" (1930). Del diálogo transtextual de las 2 revistas Qué y los manifiestos surrealistas podemos sintetizar al menos cinco aspectos que pasaremos a tratar:

\section{Crítica social y necesidad de libertad}

El surrealismo como todo movimiento vanguardista buscó instaurar una nueva moral basada en la subversión de los valores socialmente legitimados. Desde su génesis buscó liberar al hombre de la burguesía, la moral, la razón y en general de todas las reglas aceptadas y reproducidas por la sociedad, proponiendo el inconsciente como principio generador del mundo (Breton, 1992b, p. 24).

En "Primer manifiesto del surrealismo", Breton definió el surrealismo como "un dictado del pensamiento, sin la intervención reguladora de la razón, ajeno a toda preocupación estética o moral" (p. 24). Es decir, plantea rebelarse contra la razón y lo establecido; finalidad liberadora que busca "liberar a los interlocutores de las obligaciones impuestas por la buena crianza" (Breton, 1992b, p. 30).

Los textos de Qué rescatarán del surrealismo francés ese carácter subversivo: "Vomitamos inconteniblemente sobre todas las formas de resignación a este destino (cualidad máxima del espíritu burgués) y miramos con simpatía todos esos aspectos de una liberación voluntaria o involuntaria: enfermedad, locura, suicido, crimen, revolución" (Que, Pequeño 1).

El surrealismo se desarrolló en Argentina como una herramienta de liberación contra el espíritu burgués que regía la sociedad de los años 20; y permitió revalorar elementos socialmente no aceptados, algo común a los movimientos de vanguardia latinoamericana: "Si aquella suposición permite fundar esperanzas en la inconmovilidad del sistema que nos rige, la nuestra, exige una subversión de valores y un deseo incesante e intrépido de dar al traste con todas nuestras satisfacciones, nuestra felicidad, nuestra paz y nuestra complicidad con la paz interior de los hartos " (Dalid, 1930, p. 3). 
La subversión de lo establecido evidencia un malestar social: "en las formas de vivir vemos ausencia de sentido; estadios preparatorios sin finalidad; caída de cuerpos sin duración" (Trizzi, 1930, p. 2); el sujeto se rebela contra las falencias de la sociedad que le tocó habitar. Asistimos a una declaración de lucha estética, proponiendo lo irracional e ilógico como alternativa al canon de la razón: "Que brote el desconcierto. Subvertir la existencia por la conmoción. Vivimos entre verdades creadas por el error"' (Dalid, 1928, p. 2).

Qué evidenciará una visión negativa del racionalismo y la conciencia: "La conciencia. Máquina de embutidos o filtro formal" (Trizzi, 1930, p. 2). Los seres humanos son asimilados a embutidos sociales; poderosa imagen que sintetizará la crítica y conciencia social que portarán los primeros textos surrealistas de América Latina.

Los integrantes de Qué buscaron instaurar una estética que subvertía el canon literario del periodo, "el espíritu en extrema desesperación por lo imposible, que es su verdadera finalidad, vive despierto hoy más en los gritos y ya no en los ayes rimados, o en la foto versolibrista del reflejo de un ocaso en una muy quisquillosa sensibilidad" (Dalid, 1930, p. 3). Buscando "Escupir al rostro del alma poética de hoy" (p. 4). Declararon la guerra contra lo establecido cifrado en la conformidad del mundo, "abofetear con un No, a cualquier afirmación de imbécil conformidad" (p. 4). Qué se erigió como una herramienta de protesta contrahegemónica ante los valores burgueses y literarios de la sociedad argentina.

\section{Pliegue sobre sí}

En su intento por liberar al hombre de las ataduras impuestas por la sociedad, la revista Qué propuso reflexionar respecto de los rincones inconscientes del alma humana. Esta publicación invitó a los lectores a buscar dentro de sí las respuestas trascendentales del ser mediante un procedimiento psicoanalítico de introspección, lo que se anuncia desde el primer manifiesto publicado por Breton (1992b), donde definía el surrealismo como "el repliegue del espíritu sobre sí mismo" (p. 25). Este pliegue o repliegue fue asimilado por los integrantes de Qué, y se manifestó desde el editorial del primer número: "Justificación de nosotros: Seres atraídos hacia sí mismos por una extraordinaria fuerza centrípeta" (Qué, Pequeño 1). Como lo indica la cita, estos autores buscaron la verdadera expresión del hombre dentro de sí mismos. El concepto de introspección fue clarificado como "una manera de dejarse poseer por uno mismo" (Qué, Pequeño 1). La introspección de la revista Qué se planteará como una interpretación sicoanalítica del primer manifiesto de Breton.

En el segundo número de la revista se presentarán dudas acerca del proceso introspectivo que comenzaran sus integrantes hacía dos años. La sociedad ha traspasado las estructuras mentales, por lo que aquello que buscaban dentro de sí, rearticulará de manera inconsciente las estructuras sociales que buscaron eludir, pasando a formar parte de lo que criticaban: "CONTENER, EXPLICAR Y SI ES POSIBLE RESOLVER, UN ESTADO DE ESPÍRITU EXCEPCIONALMENTE ABUNDANTE EN ESTA ÉPOCA, pero que por orgullo o cobardía se refugia en el aislamiento" (Este y Lagos, 1930, p. 1). 
El primer número de la revista Qué planteaba en 1928 una filiación ortodoxa a los postulados surrealistas de Breton, en relación con la importancia sicoanalítica del inconsciente, accediendo a él por medio de la "introspección". En el segundo número, en cambio, estos planteamientos iniciales fueron adaptados y problematizados al contexto social, pasando a considerar la introspección como algo negativo. No debemos olvidar la crisis económica de 1929, lo que probablemente llevó a los autores a abordar y cuestionar sus problemáticas sociales, evidenciando la necesidad de abandonar la introspección individual, en función de un colectivo que articule un discurso social.

\section{Epistemología del lenguaje}

Algo que no se expresa en los primeros manifiestos del surrealismo francés es el cuestionamiento epistemológico al lenguaje, lo que sí será abordado por Qué desde el primer momento: "Toda palabra está en el corazón mismo de los problemas del ser. Es decir, que para un hombre determinado, su misterio toma la forma de sus palabras (en un sentido más amplio: toma la forma de sus signos)" (Qué, Pequeño 1).

La palabra será la base y estará presente en sus principales reflexiones, ya que según Lagos las palabras son portadoras del misterio del alma humana, "Al pronunciar la palabra más insignificante, los remotos misterios se aproximan, y las concavidades se enderezan para que los hombres conozcan el secreto de las oscuridades aplanadas" (Lagos, 1930, p. 4), planteando una metarreflexión en el lenguaje y la capacidad evocativa de la imagen poética. Estamos ante una apología del lenguaje y su carácter místico invocador.

La palabra poseerá un sentido mágico y "una vida infinita que escapa al control lógico del hombre. Ellas nutren el sentido mágico de lo que no existe. PALABRA ES MAGIA" (Dalid, 1930, p. 3). Asistimos a la gestación de un nuevo lenguaje, que inaugura en la revista una nueva forma de relación con el mundo.

La articulación o modulación de este nuevo lenguaje será violenta, engendrando nuevos signos y sueños: "la surgente e hirviente necesidad de machacar nuestras lenguas y romper los huesos de nuestras ideas, para decir, de sueños nuevos, con signos recién forjados por los dedos doloridos" (Dalid, 1930, p. 3). El lenguaje con un comienzo sangriento, inaugura una forma de nombrar el mundo, creando y destruyendo al mismo tiempo. Se destruye lo anterior para instalar lo nuevo.

En esta relación epistemológica del lenguaje, la semántica de los textos presentará las palabras, el sueño y el inconsciente como sinónimos, ya que permitirán en la dinámica interna de los textos, analizar y develar los matices del alma humana. Desde esta perspectiva, podemos afirmar que el surrealismo de Qué al plantear el cuestionamiento epistemológico a los fundamentos del lenguaje, se distancia del surrealismo francés que no incorporará este planteamiento hasta textos posteriores. 


\section{Público y recepción}

En el primer número de Qué no aparece ninguna mención al tipo de espectador al que se dirige, algo que cambiará significativamente en la segunda publicación. En el segundo número de Qué vemos una conciencia y reflexión del público al que se dirige la revista: "la Insatisfacción llega en un instante a alterar el mecanismo anímico creando un tipo particular al cual nos dirigimos" (Este y Lagos, 1930, p. 1). El lector al que se dirige es un insatisfecho, alguien que no se ajusta a los moldes que la sociedad busca imponer. Breton (1992b) en el 'Primer manifiesto del surrealismo' también caracterizará implícitamente al lector como un insatisfecho: "El surrealismo, tal como yo lo entiendo, declara nuestro inconformismo absoluto con la claridad" (p. 35).

En las páginas del segundo número de la revista habrá una reflexión acerca del estancamiento de la literatura argentina, las escuelas y prácticas literarias; con una honestidad total se analizará y criticará la literatura argentina del periodo: "¿quiénes sino cuasiindividualistas literatuelos y presumidos melenudos leerán estás líneas? Esta es nuestra ridícula tragedia, la de pretender algo de quienes sabemos de antemano hundidos en la gozosa contemplación de su mugre, y sabernos, a nosotros mismos enfrascados, a ratos, en contemplación similar" (Dalid, 1930, p. 3).

Lo interesante de esta crítica, es que implica conocimiento y disgusto por la recepción del primer número. La "ridícula tragedia" mencionada en la cita anterior, enfatiza el hecho de que los lectores de la revista fueran precisamente los intelectuales "melenudos" contra los que se rebelaron; aporía que los llevará a cuestionar y criticar los fundamentos de la revista, y tal vez sea la razón por la que no continuaron publicando Qué.

Basado en lo anterior, podemos afirmar que el surrealismo latinoamericano de Qué se presentó más crítico y cuestionador que los manifiestos franceses. Los textos de Qué incorporaron cuestionamientos a los fundamentos esenciales del lenguaje y, al público y la recepción de la revista, cuestionamientos que no están presentes en los manifiestos franceses.

\section{Estética del sueño}

Desde el manifiesto de 1924 Breton plantea la reivindicación del sueño “¿Cuándo llegará, señores lógicos, la hora de los filósofos durmientes?” (Breton, 1992b, p. 20), lo que tendrá una repercusión directa en la estética surrealista de Qué. Breton llevará el sueño al mismo nivel de la conciencia y le asignará un sentido práctico: "¿Por qué no espero de los indicios del sueño más lo que espero de mi grado de conciencia, de día en día más elevado? ¿No cabe acaso emplear también el sueño para resolver los problemas fundamentales de la vida?" (Breton, 1992b, p. 20).

Basándose en el primer manifiesto, Qué esboza su propia estética del sueño, ya que en oposición a los manifiestos de Breton en los que pareciera igualarse el sueño a la conciencia, los surrealistas argentinos declararán la superioridad del sueño respecto de la 
realidad, cito a Dalid (1930): "Mientras tanto, gritaremos y demostraremos la preeminencia del Sueño sobre la realidad y la trascendente realidad del Sueño" (p. 4).

Las páginas de la revista evidenciarán una interpretación singular del primer texto de Breton, profundamente arraigada en la realidad argentina. Hay un análisis de la sociedad literaria del periodo, denunciando lo caduco de sus pensamientos, de aquí la necesidad de una nueva estética que renueve el panorama literario argentino: "Caducidad de las formas de la sociedad y de sus ideas, y de su expresión y más que nada, caducidad de sus sueños" (p. 3). Ante la "caducidad" social surge la necesidad de crear nuevos sueños; "para la revolución de los sueños no conocemos partidarios, ni oímos propagandistas" (p. 3). Pretendieron cambiar la realidad mediante la apología y revolución del sueño.

\section{CONCLUSIONES}

Se seleccionaron 8 textos representativos que evidencian y problematizan la estética surrealista de la revista Qué. Estos textos dialogaron transtextualmente con los textos fundacionales de Breton, el "primer" y "segundo" manifiesto del surrealismo, obteniendo de este diálogo 5 características representativas del surrealismo de Qué.

Del análisis podemos destacar tres puntos en común: 1. Crítica social y necesidad de libertad; 2. Pliegue sobre sí y 3. Estética del sueño. De estas semejanzas podemos deducir que el surrealismo de Qué, al igual que el de Breton, buscó la libertad del hombre por sobre todas las ataduras sociales. Al sumergirse dentro de sí mismos, los autores se refugiaron en el inconsciente, fuente inagotable de imágenes poéticas; destacando el predominio del sueño y lo irracional sobre la razón.

Las diferencias se presentaron en dos puntos: 3. Epistemología del lenguaje y, 4. Público y recepción. Desde el primer número de Qué se plantea un cuestionamiento a los fundamentos epistemológicos del lenguaje y, desde el segundo número, vemos una crítica a los receptores de la revista. Esto nos llevará a afirmar que el surrealismo de Qué fue más crítico que el surrealismo de Breton, lo que podría explicarse debido a la crisis económica de 1929 que impulsó a los autores a cuestionar y repensar la sociedad, abandonando el ensimismamiento planteado en el primer número de la revista.

Tras constatar los receptores que tuvo la primera aparición de Qué, es posible que los autores se hayan decepcionado, ya que fueron leídos por el canon que criticaban. Podríamos afirmar, a modo de especulación, que esta fue una razón relevante para no continuar con la publicación de la revista.

Para finalizar, podemos afirmar que si bien el surrealismo de Qué compartió varias características con el modelo francés, también se diferenció de este, portando un sentido mucho más crítico; constituyendo un corpus homogéneo claramente reconocible entre los movimientos surrealistas latinoamericanos. 
Rasgos transtextuales del surrealismo argentino en Revista Qué

Universidad Central de Chile

Magister en Estudios Latinoamericanos

Avda. Francisco de Aguirre \#0405, La Serena (Chile)

fgamboa85@gmail.com

\section{OBRAS CITADAS}

Anónimo. (1928). "Pequeño esfuerzo de justificación colectiva". Qué, 1-2.

Baciu, Stefan. (1979). Surrealismo latinoamericano. Preguntas y respuestas. Valparaíso: Ediciones Universitarias de Valparaíso.

Breton, André. (1992a). "Segundo manifiesto surrealista" (1930). En: Breton, André. Manifiestos del surrealismo. Traducción y notas de Aldo Pellegrini. Buenos Aires: Argonauta, 43-54.

— (1992b). "Primer Manifiesto del Surrealismo" (1924). En: Breton, André. Manifiestos del surrealismo. Traducción y notas de Aldo Pellegrini. Buenos Aires: Argonauta, 19-41.

Dalid, Esteban. (1930). "Respuesta". Qué 2, 2.

— (1930). "Manifiesto". Qué 2, 3-4.

— (1928). 'Pretexto'. Qué 1, 2.

De Sola, Graciela. (1967). Proyecciones del surrealismo en la República Argentina. Buenos Aires: Culturales Argentinas.

Este, Adolfo y Lagos, Filidor. (1930). "Por esta puerta abierta los señores pueden entrar en el recinto de los fantasmas". Qué 2, 1.

Genette, Gérard. (1989). Palimpsestos: la literatura en segundo grado. Barcelona: Taurus.

Lagos, Filidor. (1930). "Libertinaje de los solenoglifos, y otras cosas dichas entre dientes". Qué2, 4-6.

Méndez, Rubén Daniel. (2002). "Aldo Pellegrini y el surrealismo". Congreso Brasileño de Hispanistas, Octubre.

Sarlo, Beatriz. (1969). Martín Fierro (1924-1927). Antología y prólogo. Buenos Aires: Carlos Pérez.

Trizzi, Julio. (1930). “Molestia. Como si fuera una aclaración para mí” Qué 2, 2.

—_ (1928). "Soluciones". Qué 1, 15. 